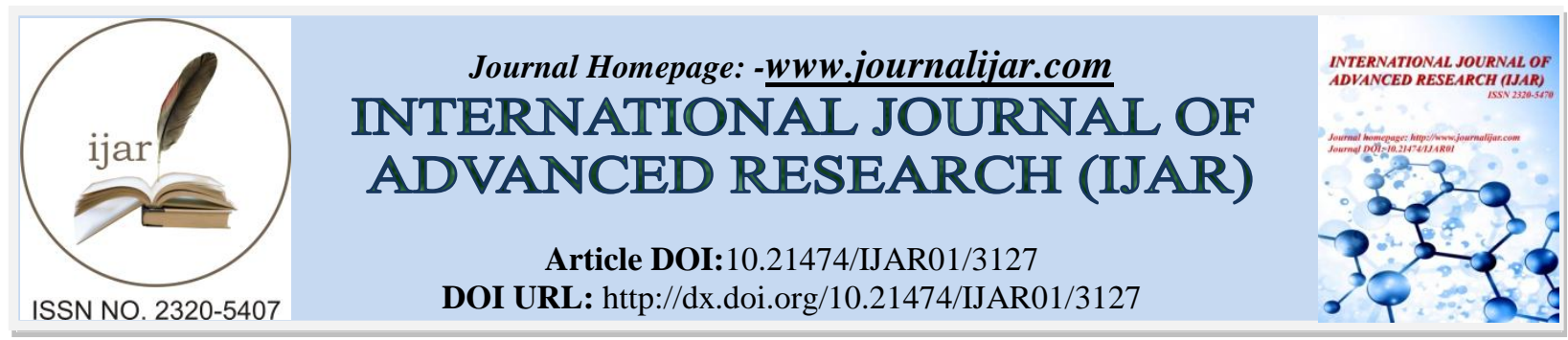

RESEARCH ARTICLE

\title{
PROVIDING PREVENTIVE ADVICE BY DENTAL HYGIENIST, AND PREVENTIVE METHODS OF ORAL DISEASES AMONG ADULTS, IN KINGDOM OF SAUDI ARABIA.
}

\author{
Abdullah Hadi O Almataif, Turki Farhan Alharbi, Yahya Ahmed Ali Alfathy Assiri and Fawaz Ali \\ Mohammad Alghamdi. \\ Kingdom of Saudi Arabia, King Abdul Aziz University, Faculty of Dentistry.
}

\section{Manuscript Info}

Manuscript History

Received: 05 December 2016

Final Accepted: 07 January 2017

Published: February 2017

\begin{abstract}
Purpose: study to assess the performance of dental hygienists for their role at providing preventive advice to patients and assess preventive methods of oral diseases among adults in kingdom of Saudi Arabia.

Methods: A self-administered questionnaire was conducted electronically through social media websites and WhatsApp application. This study include randomly selected (658) participants from all kingdom of Saudi Arabia population.

Results: $51.5 \%$ visit private dental centers. $41.5 \%$ reported that dental hygienists had never talk to them. $46 \%$ usually commitment the advices of dental hygienists related to their teeth and oral health. $44.2 \%$ agreement that using miswak obviates using toothbrush and toothpaste. $91 \%$ believe that they can't use another family member's brush. 55.3\% aren't smokers. $21 \%$ suffer bad mouth smell usually. 35.5\% use toothbrush for other purposes as tongue cleaning or massage their gum. Conclusion: There is shortening by dental hygienists in providing preventive advice to patients. Moderate awareness and practice of prevention methods among adults in kingdom of Saudi Arabia.
\end{abstract}

Copy Right, IJAR, 2017,. All rights reserved.

\section{Introduction:-}

Optimal oral health care is attained when all members of the oral health care team work effectively together (1). As the public's oral health care needs change, the scope of practice in which oral health care providers can practice adapts to accommodate those changes. It is important to periodically evaluate the utilization of all members of the oral health care team to ensure the changing scope of practice is effective in providing for the public (2). Dental hygienists are highly educated professionals who complete rigorous training and meet strict standards of competency and practice (3). Dental hygienists have a specific scope of clinical procedures they provide to their patients. They assess a patient's condition in order to offer patient-specific preventative and educational services to promote and maintain good oral health.

The use of therapeutic methods assists their patients in controlling oral disease, while providing tailored treatment plans that emphasize the importance of behavioral changes (4). The complex professional role of the dental hygienist is often misunderstood other healthcare professionals (5). Furthermore, how the dental hygienist is utilized in the general dental practice is highly variable (2). Although clinical responsibilities vary based on individual state's scope of practice rules and regulations, the dental hygienists' role as a prevention specialist is constant throughout 
regions. Dental hygienists are trained to assess risk, educate and help patients manage and reduce risk for oral diseases (6).

Oral health is an integral element of general health and wellbeing. Good oral health enables individuals to communicate effectively, to eat and enjoy a variety of foods, and is important in overall quality of life, self-esteem and social confidence (7). Recent decades have witnessed improvement in the oral health status in developed countries attributable to changes in dietary habits, improved oral hygiene habits, and widespread availability and use of fluorides $(8,9)$. In addition, improved awareness related to oral health has been reported in developed countries and is cited as being partly responsible for better oral health $(10,11)$. However oral diseases, particularly dental caries and periodontal disease, remain a public health challenge (12). Changing patterns in the global diseases have been linked to changing lifestyles that include diet, use of tobacco, and consumption of alcohol. Changes in these lifestyle factors have a significant impact on oral health. Therefore, oral diseases qualify as a major public health concern (13). oral diseases affect a significant proportion of the world's population and exact a heavy toll in terms of morbidity and mortality (14). A range of diseases and conditions can be classified as oral diseases including dental caries, periodontal diseases, oral cancers, noma, dental erosion and dental fluorosis (15). It has also become clear that causative or risk factors in oral disease are often the same as those implicated in the major general diseases (16). oral disease is one of the four most expensive preventable chronic diseases, and in most cases these dental diseases are preventable (17). Inadequate knowledge of available preventive methods is related to non-adoption of preventive practices (18). Adoption of preventive practices and use of preventive modalities is a key message in most health education campaigns (11).

Given the importance of the role of dental hygienists as dental professionals, and the importance of oral diseases preventive means in maintaining the oral health and avoid oral diseases in general. Inadequate data is available about performance of dental hygienists for their role at providing preventive advice to patients and preventive methods of oral diseases among adults in KINGDOM OF SAUDI ARABIA. Researcher conducted this study to assess the performance of dental hygienists for their role at providing preventive advice to patients and assess preventive methods of oral diseases among adults in KINGDOM OF SAUDI ARABIA.

\section{Aims:-}

- To assess the performance of dental hygienists for their role at providing preventive advice to patients in KINGDOM OF SAUDI ARABIA.

- And assess preventive methods of oral diseases among adults in KINGDOM OF SAUDI ARABIA.

\section{Material and methods:-}

Across-sectional was study conducted by researchers, using a questionnaire consist of twenty seven multiple-choice questions divided in to three main domains. The first domain include demographic questions dealing with age, gender, and nationality. While second domain include questions dealing with assessing the scope to which the specialist dental duties. And the third dealing with preventive procedures that carried out by the participants to maintain their oral health. This study include (658) participants from all KINGDOM OF SAUDI ARABIA population, they were selected randomly, and answered the questionnaire electronically through social media websites and WhatsApp application.

\section{Statistical methods:-}

The statistical analysis program (SPSS v.22) was been used in the study in data entry and analysis, with the use of necessary statistical methods to achieve the objectives of the study. The following statistical methods were used:

- Frequencies.

- Percentages.

- Diagrams.

- Chi Square test.

\section{Population \& Sample of the Study:-}

The study population includes all KINGDOM OF SAUDI ARABIA population, the sample was (658) randomly chosen persons, they answered the electronic questionnaire through social media websites and WhatsApp application, $87.5 \%$ of them were males, while $12.5 \%$ of them were females. Most of them were Saudi. 
And according to their ages; $72.9 \%$ of their ages were between (20 -40) years old, while $24.2 \%$ of them were more than (40) years old, and $2.9 \%$ of them were less than (20) years old. The next table illustrates that.

Table (1):- Personal data for the study sample. $(\mathrm{N}=658)$.

\begin{tabular}{|l|l|l|l|}
\hline \multicolumn{2}{|l|}{ Personal Data } & Frequency & Percent \\
\hline \multirow{3}{*}{ Gender } & Male & 576 & 87.5 \\
\cline { 2 - 4 } & Female & 82 & 12.5 \\
\hline \multirow{4}{*}{ Age } & Less than 20 year & 19 & 2.9 \\
\cline { 2 - 4 } & From 20 - 40 year & 480 & 72.9 \\
\cline { 2 - 4 } & More than 40 year & 159 & 24.2 \\
\hline \multirow{2}{*}{ Nationality } & Saudi & 637 & 96.8 \\
\cline { 2 - 4 } & Non-Saudi & 21 & 3.2 \\
\hline
\end{tabular}

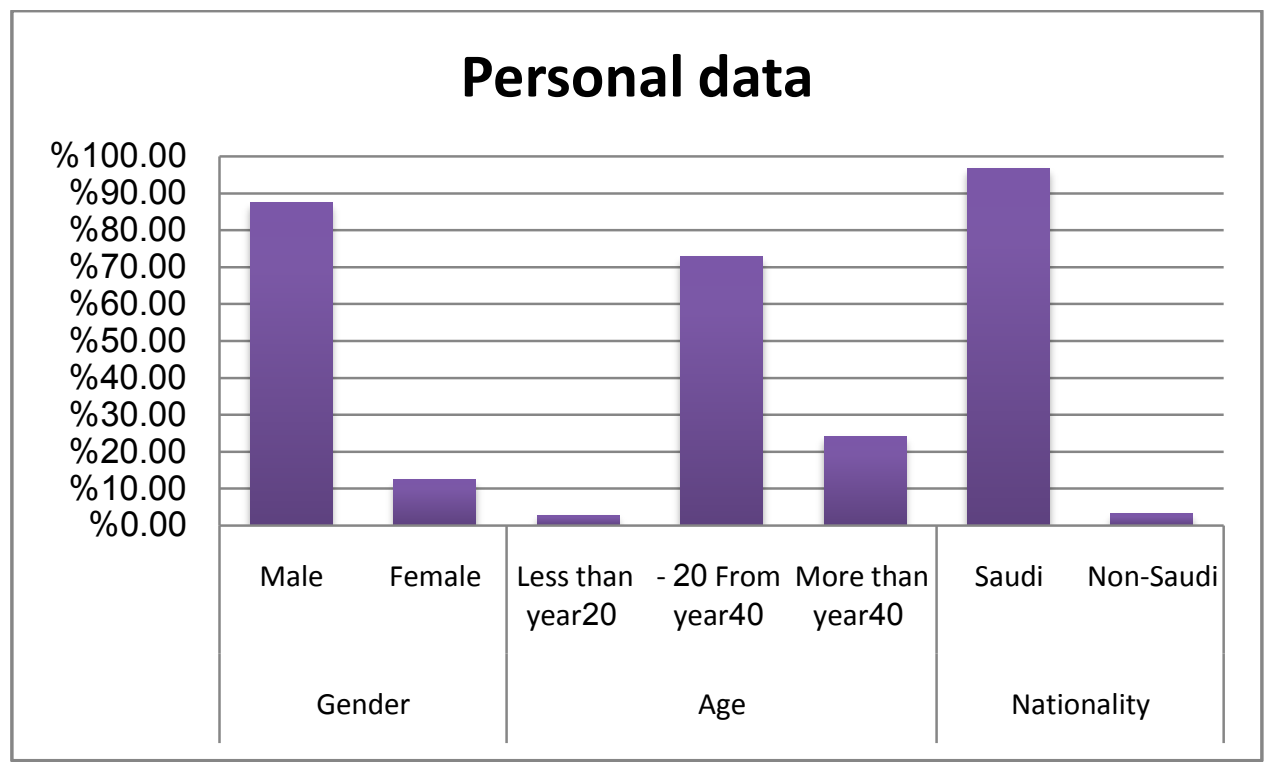

Diagram (1):- Personal data for the study sample.

\section{Results:-}

Table (2):- shows the participants' distribution according to their commitment to the visits dates of oral health to follow up gum infections.

\begin{tabular}{|l|l|l|}
\hline & Frequency & Percent \\
\hline Yes & 87 & 13.2 \\
\hline No & 351 & 53.3 \\
\hline Sometimes & 220 & 33.4 \\
\hline Total & 658 & 100.0 \\
\hline
\end{tabular}

We notice that more than half of the participants don't commit to the visits dates of oral health and following gum infections.

Table (3): shows the participants distribution according to the type of the dental center they visit.

\begin{tabular}{|l|l|l|}
\hline & Frequency & Percent \\
\hline Private & 339 & 51.5 \\
\hline Governmental & 129 & 19.6 \\
\hline Private \& Governmental & 190 & 28.9 \\
\hline Total & 658 & 100.0 \\
\hline
\end{tabular}

We notice that more than half of the participants have the oral health care in private centers, while $19.6 \%$ of them visit governmental centers. 
Table (4):- shows the participants' distribution according to whether the oral health specialist have talked to them or not.

\begin{tabular}{|l|l|l|}
\hline & Frequency & Percent \\
\hline Yes & 205 & 31.2 \\
\hline No & 273 & 41.5 \\
\hline Sometimes & 180 & 27.4 \\
\hline Total & 658 & 100.0 \\
\hline
\end{tabular}

We notice that $41.5 \%$ of the participants haven't talked to their specialist about their oral health, while the others have talked to their oral health specialist about that. The next table shows the participants (who had a talk with their oral health specialist about some cases which it is supposed to be spoken by a specialist oral and dental health of the patient, and the extent of doing so) distribution.

Table (5):- shows the participants' distribution according to having a talk with their oral health specialist about some cases which it is supposed to be spoken by a specialist oral and dental health of the patient, and the extent of

\begin{tabular}{|l|l|l|l|l|l|l|l|}
\hline The question & Yes & No & \multicolumn{2}{|l|}{ Sometimes } & P-value \\
\cline { 2 - 8 } & $\#$ & \% & $\#$ & $\%$ & $\#$ & \% & \\
\hline $\begin{array}{l}\text { Did your oral health specialist explain the } \\
\text { causes of gum infections and how they } \\
\text { relate to following the different methods of } \\
\text { keeping oral health in a good case? }\end{array}$ & 179 & 46.5 & 96 & 24.9 & 110 & 28.6 & $0.000^{* *}$ \\
\hline $\begin{array}{l}\text { Do your oral health specialist teach you the } \\
\text { right and suitable way to brush your teeth? }\end{array}$ & 178 & 46.2 & 134 & 34.8 & 73 & 19.0 & $0.000^{* *}$ \\
\hline $\begin{array}{l}\text { Do your oral health specialist explain the } \\
\text { impact of smoking and tobacco types on the } \\
\text { oral and dental health? }\end{array}$ & 176 & 45.7 & 157 & 40.8 & 52 & 13.5 & $0.000^{* *}$ \\
\hline $\begin{array}{l}\text { Do your specialist teach you the necessity } \\
\text { and how to use the dental floss? }\end{array}$ & 114 & 29.6 & 208 & 54.0 & 63 & 16.4 & $0.000^{* *}$ \\
\hline $\begin{array}{l}\text { Do your oral health specialist explain the } \\
\text { role of fluoridated toothpaste to keep the } \\
\text { oral health in a good case? }\end{array}$ & 131 & 34.0 & 168 & 43.6 & 86 & 22.3 & $0.000^{* *}$ \\
\hline $\begin{array}{l}\text { Do your oral health specialist explain the } \\
\text { impact of oral diseases on your body and } \\
\text { your heart? }\end{array}$ & 108 & 28.1 & 229 & 59.5 & 48 & 12.5 & $0.000^{* *}$ \\
\hline
\end{tabular}

** Chi square test significant at the 0.01 level.

We conclude from the previous table that $46.5 \%$ of the participants who had a talk with their oral health specialist, he explained the causes of gum infections and how they relate to following the different methods of keeping oral health in a good case, and $46.2 \%$ of them were taught about the right and suitable way to brush your teeth, $45.7 \%$ of them said that the impact of smoking and tobacco types on the oral and dental health was explained to them by the specialist.

While we find that $43.6 \%$ of the cases weren't taught the right and suitable way to brush their teeth, and $54 \%$ of them weren't told by their oral health specialist about the necessity and the way to use the dental floss, also $59.5 \%$ of them didn't have the impact of oral diseases on their body and heart explained. 
Diagram (2):- shows the participants commitment extent in following the specialist's advices related to their teeth and oral health.

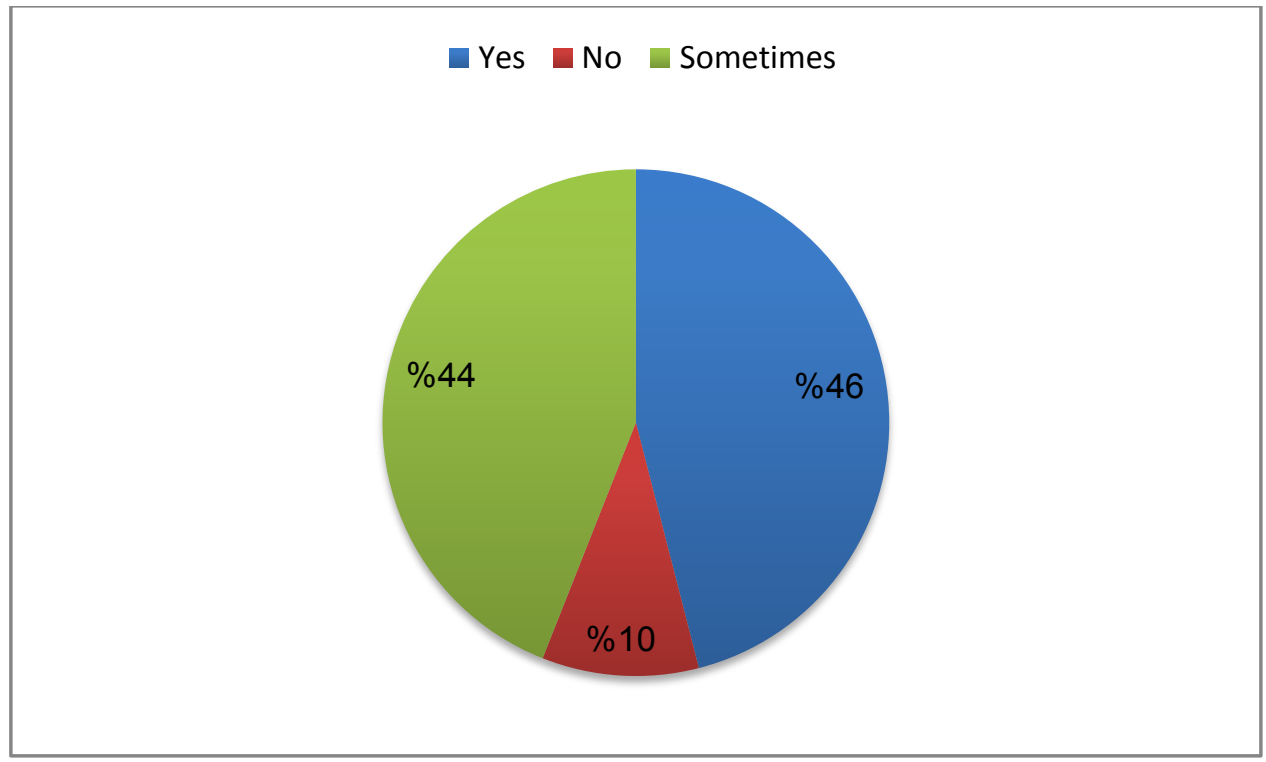

Table (6):- shows the participants distribution according to whether their dentists advised them with special toothpaste for teeth sensitivity if it happened after cleaning.

\begin{tabular}{|l|l|l|}
\hline & Frequency & Percent \\
\hline 205 & 31.2 & 205 \\
\hline 453 & 68.8 & 453 \\
\hline 658 & 100.0 & 658 \\
\hline
\end{tabular}

We notice that $60 \%$ of the participants' dentists didn't describe them special toothpaste for teeth sensitivity if it happened after cleaning.

Table (7):- the participants' distribution according the dentist advice about the number of time they should brush their teeth a day.

\begin{tabular}{|l|l|l|}
\hline & Frequency & Percent \\
\hline Once before sleeping & 41 & 6.2 \\
\hline Twice, when getting up and before sleeping & 286 & 43.5 \\
\hline After every meal & 129 & 19.6 \\
\hline He didn't advise me to do that & 202 & 30.7 \\
\hline Total & 658 & 100.0 \\
\hline
\end{tabular}

We notice that $43.5 \%$ of the participants were advised to brush their teeth twice a day, once before sleeping and once after getting up.

Table (8):- the participants' distribution according the dentist advice about the time they should replace their toothbrushes.

\begin{tabular}{|l|l|l|}
\hline & Frequency & Percent \\
\hline When the bristles begin to fade out & 62 & 9.4 \\
\hline After 3-6 months of use & 135 & 20.5 \\
\hline After flue infection or any infectious disease & 20 & 3.0 \\
\hline He didn't tell me about that & 441 & 67.0 \\
\hline Total & 658 & 100.0 \\
\hline
\end{tabular}

We notice that $67 \%$ of the participants weren't told about the suitable time to replace their toothbrushes, while $20.5 \%$ of them were advised to replace it after (3-6) months of using it. 
Table (9):- shows the participants distribution according to their agreement that using siwaak obviates using toothbrush and toothpaste.

\begin{tabular}{|l|l|l|}
\hline & Frequency & Percent \\
\hline Yes & 291 & 44.2 \\
\hline No & 265 & 40.3 \\
\hline I don't know & 102 & 15.5 \\
\hline Total & 658 & 100.0 \\
\hline
\end{tabular}

We notice that $44.2 \%$ of the participants belief that using swiaak obviates using toothbrush and toothpaste, while $40.3 \%$ of them didn't believe so.

Table (10):- shows the participants distribution according to whether they believe that they can use another family member's brush in the case of losing theirs.

\begin{tabular}{|l|l|l|}
\hline & Frequency & Percent \\
\hline Yes & 21 & 3.2 \\
\hline No & 599 & 91.0 \\
\hline I don't know & 38 & 5.8 \\
\hline Total & 658 & 100.0 \\
\hline
\end{tabular}

We find that $91 \%$ of them told that they believe that it is wrong to use others toothbrushes in case they lost theirs.

Diagram (3):- shows the participants' distribution according to whether the suffer teeth sensitivity after cleaning

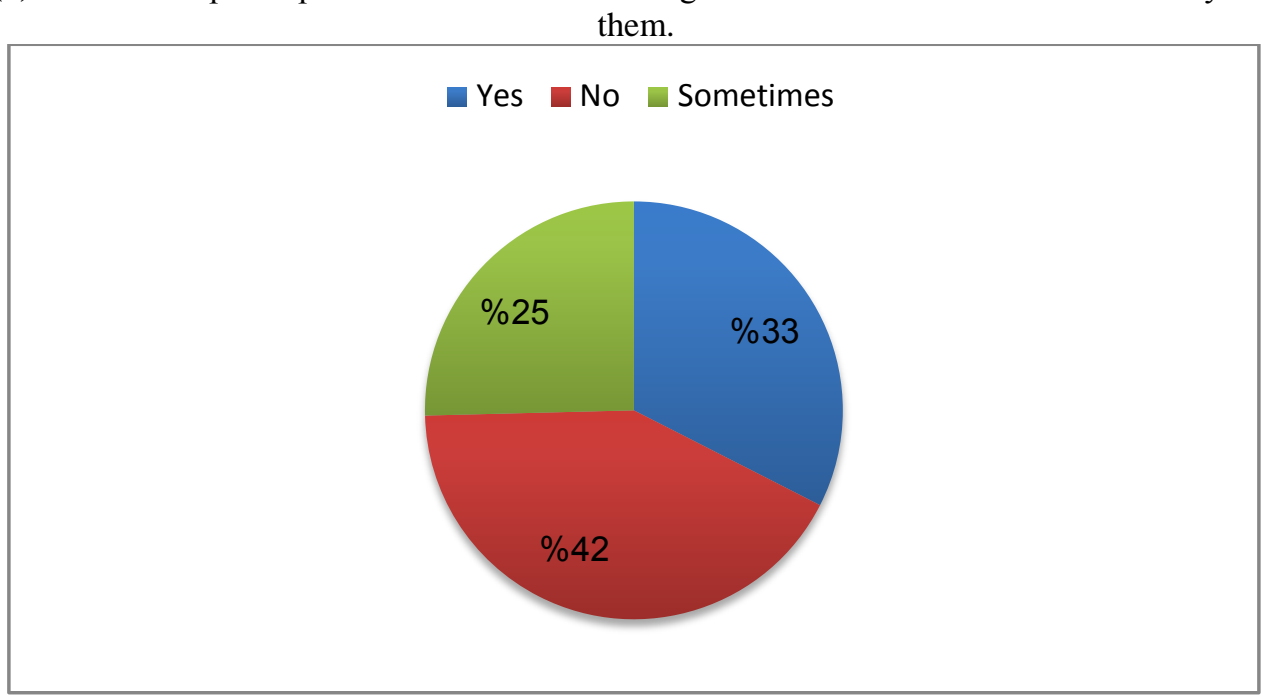

We notice that $42 \%$ of the participants don't suffer teeth sensitivity after cleaning them, while $33 \%$ of them suffer from that, and $25 \%$ of them sometimes suffer from that.

Table (11):- shows the participants' distribution in terms of doing some special oral hygiene and preventive measures.

\begin{tabular}{|c|c|c|c|c|c|c|c|}
\hline \multirow[t]{2}{*}{ The question } & \multicolumn{2}{|l|}{ Yes } & \multicolumn{2}{|l|}{ No } & \multicolumn{2}{|c|}{ Sometimes } & \multirow[t]{2}{*}{ P-value } \\
\hline & \# & $\%$ & \# & $\%$ & \# & $\%$ & \\
\hline $\begin{array}{l}\text { Do you use special toothpastes for } \\
\text { sensitivity? }\end{array}$ & 169 & 25.7 & 361 & 54.9 & 128 & 19.5 & $0.000 * *$ \\
\hline $\begin{array}{l}\text { Do you periodically check your gum's } \\
\text { health state (inflammation, bleeding and } \\
\text { inflation or landing that causes tooth } \\
\text { sensitivity? }\end{array}$ & 114 & 17.3 & 383 & 58.2 & 161 & 24.5 & $0.000 * *$ \\
\hline $\begin{array}{l}\text { Do you follow the specialist instructions to } \\
\text { use mouth rinse or antiseptic oral solution? }\end{array}$ & 224 & 34.0 & 229 & 34.8 & 205 & 31.2 & 0.481 \\
\hline
\end{tabular}

** Chi square test significant at the 0.01 level.

We conclude from the previous table that $54.9 \%$ of the participants don't use special toothpastes for sensitivity, $58.2 \%$ of them don't periodically check their gum's health state (inflammation, bleeding and inflation or landing 
that causes tooth sensitivity, also we notice that $34.8 \%$ of them don't follow the specialist instructions to use mouth rinse or antiseptic oral solution, while $34 \%$ of them do, and $31.2 \%$ of them rarely follow the specialists instructions to do that.

Diagram (4):- shows the participants worry extent when they visit the dental clinic:

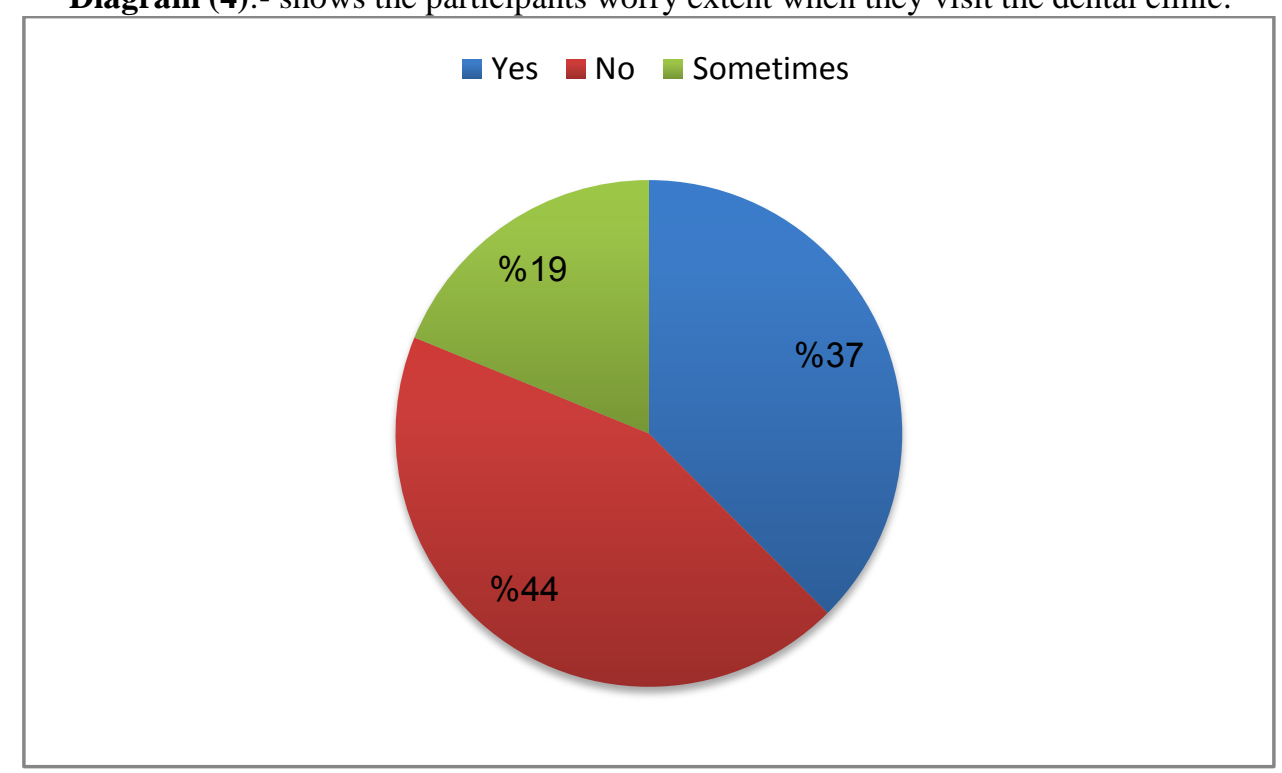

We notice that $44 \%$ of the participants don't feel worried when visiting the dental clinic, while $34 \%$ of the do, and $19 \%$ of them sometimes feel worried when visiting the dental clinic.

Table (12):- shows the participants' distribution in terms of smoking and mouth cleaning habits.

\begin{tabular}{|l|l|l|l|l|l|l|}
\hline The question & Yes & No & \multicolumn{2}{l|}{ Sometimes } \\
\cline { 2 - 7 } & $\#$ & $\mathbf{\%}$ & $\#$ & $\mathbf{\%}$ & $\#$ & \% \\
\hline Do you smoke or use any tobacco types? & 249 & 37.8 & 364 & 55.3 & 45 & 6.8 \\
\hline Do you suffer any bad mouth smell? & 138 & 21.0 & 284 & 43.2 & 236 & 35.9 \\
\hline $\begin{array}{l}\text { Do you use toothbrush for other purposes as } \\
\text { tongue cleaning or massage your gum? }\end{array}$ & 230 & 35.0 & 320 & 48.6 & 108 & 16.4 \\
\hline
\end{tabular}

We notice that $55.3 \%$ of the participants are not smokers and don't use any other types of tobacco, also we conclude that $43.2 \%$ of them don't suffer any mouth bad smell, while $35.9 \%$ of them sometimes suffer from bad mouth smell, and $21 \%$ of them already suffer from bad mouth smell.

Also we notice that $48.6 \%$ of the participants don't use their toothbrushes for other purposes, while $35 \%$ of them do.

\section{Discussion:-}

Oral health is an integral part of overall health and well-being. And oral disease is one of the four most expensive preventable chronic diseases (17). Dental hygienists are trained to assess risk, educate and help patients manage and reduce risk for oral diseases (6). So dental hygienists, as the primary preventive specialists of the dental team (20).In these topics data is rather scarce, especially in Saudi Arabia. Accordingly, the study was conducted to assess the performance of dental hygienists for their role at providing preventive advice to patients and assess preventive methods of oral diseases among adults in KINGDOM OF SAUDI ARABIA.

The majority of participants at this study were males. While the bulk of the participants ranged in age from 20 - 40 year old. And the most common nationality was Saudi. More than half of participants visit private dental center. This is a point we need to stop and then find out the cause of direction of most dental patients towards private sector. If there is a failure in the government sector must be dealt with. 
Based on our results the dental hygienists didn't their required duty at providing advices to their patients, and provide them with preventive methods to avoid oral diseases. Whereas $41.5 \%$ of participants reported that dental hygienists had never talk to them. While only $27.4 \%$ reported that dental hygienists talk to them sometimes.

Despite increased access to water fluoridation, widespread use of fluoride toothpaste, and health-promotion efforts, periodontal disease, remain a public health challenge(12). And many previous epidemiological studies estimated that the prevalence of adult gingivitis varies from approximately $50-100 \%$ for dentate patients (21). We found from participants whose reported that dental hygienists talk to them about $24.9 \%$ reported that dental hygienists didn't explain the causes of gum infections and how they relate to following the different methods of keeping oral health in a good case for them.

Despite dental professionals should encourage patients' self-confidence to brush and floss at recommended levels and discuss strategies that combat barriers to performance(22).from the participants who had spoken to dental hygienists, 34.8\% reported that dental hygienists didn't teach them the right and suitable way to brush their teeth. While more than half reported that dental hygienists didn't teach them the necessity and how to use the dental floss. From the participants who had talk to dental hygienists, $40.8 \%$ reported that dental hygienists didn't explain the impact of smoking and tobacco types on the oral and dental health for them. Although the Smoking is a risk factor for poor oral health and oral diseases (23).

Daily tooth brushing with fluoridated toothpastes is important for preventing dental caries (24). However $43.6 \%$ reported that dental hygienists didn't explain the role of fluoridated toothpaste to keep the oral health in a good case. A large number of publications have suggested that oral infection, especially periodontitis, are a potential contributing factor to a variety of clinically important systemic diseases (25). its mean that good oral health is important not only to prevent oral disease but also to maintain good general health. However 59.5\% reported that dental hygienists didn't explain the impact of oral diseases on their body and heart.

Generally only $10 \%$ didn't follow the specialist's advices related to their teeth and oral health.

Given that these percentages mentionedpreviously referto part from the participants who had spoken to dental hygienists not from all participants, If compared with the total number of participants, it will show the extent of the negligence of dental hygienists in providing advice to patients. Ghasemiet al., reported at their study in Iran that dentists' knowledge of and attitudes towards prevention should be improved and updated to enable and encourage them to provide their patients with preventive care (26).

Concerning awareness of prevention methods. Adequate awareness is a necessary enabling factor for self-care which can prevent and/or control many oral diseases (27). The results showed moderate and awareness practice of prevention methods among participants. While Al-Ansari found that preventive methods is not prevalent among Saudi adults.

$44.2 \%$ of the participants belief that using miswak obviates using toothbrush and toothpaste. When used properly, the miswak is reported to be as effective as a toothbrush $(29,30)$. The mode of transmission of cariogenic bacteria appears to be contact, either direct or indirect. Direct contact is commonly by kissing, so that oral flora is transmitted in saliva; indirect contact occurs via objects such as a cup, utensils, toothbrush, or even shared toys, which are contaminated with cariogenic bacteria $(31,32,33)$.In this study the vast majority believe that they can use another family member's brush in the case of losing theirs.

$34 \%$ of the participants feel worried when visiting the dental clinic, this finding close to Al-Dosari who found that $35 \%$ with dental fear in KINGDOM OF SAUDI ARABIA (34). In Australia, High dental fear affects approximately one in six Australian adults (35).

Smoking is a risk factor for poor oral health and oral diseases (23). One of the reports published about smoking status in Saudi Arabia suggests a wide range for the prevalence of smoking (2.4-52.3\%) (36). In the present study, $37.8 \%$ were found to be currently smoking. This value is on the higher side of the range mentioned. Oral and dental health care of non-smokers has been found to be better than that of smokers (37). A direct correlation was found to exist between oral hygiene practices and oral hygiene conditions associated with halitosis (38). $21 \%$ of the participants suffer any bad mouth smell. 


\section{Conclusion:-}

Dental hygienists didn't their required duty at providing advices to their patients, and provide them with preventive methods to avoid oral diseases. The results showed moderate awareness and practice of prevention methods among adults in KINGDOM OF SAUDI ARABIA.

\section{Recommendations:-}

- Conduct training for dental hygienists about the importance of and how to provide preventive advice to patients.

- Study the cause of the failure of the dental hygienists, in turn, to provide preventive advice to patients.

- Need to increase the awareness of smoke-related problems and target the smokers group with smoke cessation programs.

\section{References:-}

1. Pritzel, S. J., and T. G. Green. "Working relationship between dentists and dental hygienists: their perceptions." Journal of dental hygiene: JDH/American Dental Hygienists' Association 64.6 (1989): 269-272.

2. Mishler, Samantha K. General Dentists' Perceptions of the Professional Role of the Dental Hygienist within the Private Practice Setting. Diss. University of Michigan, 2016.

3. Golubovic, Aleksandra. The Aliment of Anxiety: Nutritional Advice Pertaining to Sugar in Post-WWII Canada. Diss. 2014.

4. Cormac, Irene. "The role of health professionals." Essentials of Physical Health in Psychiatry (2012): 43.

5. Ateah, Christine A., et al. "Stereotyping as a barrier to collaboration: Does interprofessional education make a difference?." Nurse education today 31.2 (2011): 208-213.

6. American Dental Association. "Commission on Dental Accreditation. Accreditation standards for dental education programs." Chicago, ADA, December 1985 (2007).

7. Locker, D. "Measuring oral health: a conceptual framework." Community dental health 5.1 (1988): 3-18.

8. World Health Organization. "Global oral health data bank." Geneva: World Health Organization (2002).

9. Bratthall, Douglas, Gunnel Hänsel-Petersson, and Hans Sundberg. "Reasons for the caries decline: what do the experts believe?." European journal of oral sciences 104.4 (1996): 416-422.

10. Vigild, M., P. E. Petersen, and R. Hadi. "Oral health behaviour of 12-year-old children in Kuwait." International Journal of Paediatric Dentistry 9.1 (1999): 23-29.

11. Zhu, Ling, et al. "Oral health knowledge, attitudes and behaviour of adults in China." International dental journal 55.4 (2005): 231-241.

12. Taylor, Jane, and Fiona a Blinkhorn. "assessment of the management factors that influence the development of preventive care in the new south Wales public dental service." Journal of Healthcare Leadership 7 (2015): 111.

13. Petersen, Poul Erik. "Challenges to improvement of oral health in the 21st century-the approach of the WHO Global Oral Health Programme." International dental journal 54.S6 (2004): 329-343.

14. Petersen, Poul Erik. "The World Oral Health Report 2003: continuous improvement of oral health in the 21st century-the approach of the WHO Global Oral Health Programme." Community Dentistry and oral epidemiology31.s1 (2003): 3-24.

15. Watt, Richard G. "Strategies and approaches in oral disease prevention and health promotion." Bulletin of the World Health Organization 83.9 (2005): 711-718.

16. Who, Joint, and FAO Expert Consultation. "Diet, nutrition and the prevention of chronic diseases." World Health Organ Tech Rep Ser 916.i-viii (2003).

17. Australian Institute of Health and Welfare. Australia's Health 2014. Canberra: AIHW; 2014.

18. Shekar, BR Chandra, et al. "Dental health awareness, attitude, oral health-related habits, and behaviors in relation to socio-economic factors among the municipal employees of Mysore city." Annals of Tropical Medicine and Public Health 4.2 (2011): 99.

19. Zhu L, Petersen PE, Wang HY, Bian JY, Zhang BX. Oral health knowledge, attitudes and behavior of adults in China. Int Dent J. 2005;55:231-41.

20. Francisco, Elena M., et al. "Dental hygienists' knowledge, attitudes and practice behaviors regarding caries risk assessment and management." American Dental Hygienists Association 87.6 (2013): 353-361.

21. Idrees, Majdy M., et al. "Prevalence and severity of plaque-induced gingivitis in a Saudi adult population." Saudi medical journal 35.11 (2014): 1373. 
22. Buglar, Maria E., Katherine M. White, and Natalie G. Robinson. "The role of self-efficacy in dental patients' brushing and flossing: testing an extended Health Belief Model." Patient education and counseling 78.2 (2010): 269-272.

23. Bukmir, Romana Peršić, Marija Jurčević Grgić, and Sonja Pezelj-Ribaric. "Influence of tobacco smoking on dental periapical condition in a sample of Croatian adults." Wiener klinische Wochenschrift 128.7-8 (2016): 260-265.

24. Twetman, Svante, et al. "Caries-preventive effect of fluoride toothpaste: a systematic review." Acta Odontologica Scandinavica 61.6 (2003): 347-355.

25. Li, Xiaojing, et al. "Systemic diseases caused by oral infection." Clinical microbiology reviews 13.4 (2000): 547-558.

26. Ghasemi, Hadi, et al. "Knowledge of and attitudes towards preventive dental care among Iranian dentists." European journal of dentistry 1.4 (2007): 222.

27. Burt, Brian A., and Steven A. Eklund. Dentistry, dental practice, and the community. Elsevier Health Sciences, 2005.

28. Al-Ansari, Asim. "Awareness, utilization, and determinants of using oral diseases prevention methods among Saudi adults-a clinic-based pilot study." International journal of health sciences 10.1 (2016): 77.

29. Al Sadhan, Ra'ed I., and Khalid Almas. "Miswak (chewing stick): a cultural and scientific heritage." Saudi Dental Journal 11.2 (1999): 80-87.

30. Sadat Tabatabaei, Fahimeh, Maryam Moezizadeh, and Fateme Javand. "Effects of extracts of Salvadora persica on proliferation and viability of human dental pulp stem cells." Journal of conservative dentistry: JCD 18.4 (2015): 315 .

31. Sakai, Vivien T., et al. "Knowledge and attitude of parents or caretakers regarding tr1ansmissibility os caries disease." Journal of Applied Oral Science 16.2 (2008): 150-154.

32. Chan, K. M., N. M. King, and N. M. Kilpatrick. "Can infants catch caries? A review of the current evidence on the infectious nature of dental caries in infants." NZ Dent J 101.1 (2005): 4-11.

33. Newbrun, Ernest. "Preventing dental caries: breaking the chain of transmission." The Journal of the American Dental Association 123.6 (1992): 55-59.

34. Al-Dosari, A. M. "Dental Fear among visitors of Primary Healt h Care Centers in Saudi Arabia." OdontoStomatologie Tropical e 11 (1996): 9.

35. ARCPOH. "Australian Research Centre for Population Oral Health." (2001).

36. Bassiony, Medhat M. "Smoking in Saudi Arabia." Saudi medical journal 30.7 (2009): 876-881.

37. Peker, Ilkay, and Meryem Toraman Alkurt. "Oral health attitudes and behavior among a group of Turkish dental students." European journal of dentistry 3.1 (2009): 24.

38. Setia, Saniya, et al. "Correlation of oral hygiene practices, smoking and oral health conditions with self perceived halitosis amongst undergraduate dental students." Journal of natural science, biology, and medicine 5.1 (2014): 67. 